ARTICLE

Received 19 Dec 2014 | Accepted 19 Feb 2015 | Published 24 Mar 2015

DOI: $10.1057 /$ palcomms.2015.6

OPEN

\title{
The real vampires of New Orleans and Buffalo: a research note towards comparative ethnography
}

John Edgar Browning ${ }^{1}$

ABSTRACT This research note is an elaboration of my ethnographic work of the last 5 years and is here presented to raise careful discussion of the little-explored identity and phenomenon of "real vampirism". An auxiliary purpose of these preliminary findings is to draw attention specifically to a yet unexplored dimension of the real vampire identity: geographical specificity. This line of enquiry is informed by the intensive ethnographic fieldwork I conducted in 2009-2011 in the New Orleans metropolitan area, and by supplementary ethnographic work in 2011-2013 in Buffalo, New York. Also explored is what I term "defiant culture", through which, I posit, vampire self-identification is able to achieve a measure of empowerment by resisting "normalcy" while critiquing and challenging the power structures that re/produce it.

${ }^{1}$ School of Literature, Media, and Communication, Georgia Institute of Technology, Atlanta, USA (e-mail: john.browning@lmc.gatech.edu) 


\section{Introduction}

offer the following research note, not as a complete report, but as an elaboration of my work over the last 5 years with the aim of raising careful discussion and consideration of what has come to be known, critically, as the "real vampire community", which boasts of members in several countries, from the United States and England to Russia and South Africa. With this general thematic in mind, an auxiliary purpose of my preliminary findings is to draw attention specifically to a yet unexplored dimension of the real vampire identity: geographical specificity. This line of enquiry is informed by the intensive ethnographic fieldwork I conducted in 2009-2011 in the New Orleans metropolitan area, and by supplementary ethnographic work in 20112013 in Buffalo, New York. In the end, however, I generate what are seemingly more questions than answers, answers which I hope to remediate through further analysis with the help of current and future scholars engaged in this research.

I will begin first by outlining a brief history of the real vampire community and the literature treating it. Then, after addressing my study methodology, tools and documents, I will situate real vampirism in tandem with film, fiction and other categories in which popular culture traditionally situates monstrous figures and consider afterwards the various ways in which the figure of the vampire has been appropriated by and adapted to the real vampire community. I will then attempt to elucidate what insights vampire self-identification in particular sites like New Orleans and Buffalo yield about identity construction. Finally, after examining particular constructions like "subculture", "deviance", and my term, "defiant culture", I will address whether the participants at these sites can aid in making visible normative ideological structures while creating for themselves new and complex opportunities for agency in a world in which they are routinely outcast.

\section{Community history and literature}

The umbrella term "real vampire community" is used to describe "modern vampires" or "real vampires", 1 terms that refer interchangeably to people who consume human and/or animal blood (sanguinarian), absorb psychic energy (psychic vampire or psivamp) or both (hybrid), and do so out of a need that, according to my study participants, begins to manifest around puberty and derives from the lack of subtle energies their bodies produce. This self-described nature is a condition for which they claim to be given neither a choice nor the freedom to change. Moreover, should they refrain from feeding on blood or energy, they attest to feeling weak and experiencing an overall diminished health. What real vampirism is not, however, is the sole adoption of Gothic dress and prosthetic fangs for aesthetic purposes, as though real vampirism were merely a practice or fad that one might adopt one day and discard the next. Such a description denotes an entirely different class of people, which the real vampire community has termed "lifestylers". To real vampires, Gothic or dark clothing and fangs are, as I will explain in more detail later, merely supplementary identificatory markers of, or hegemonic modes of group expression for, their inherent condition (much in the same way that same-sex desire, for example, is categorically distinct from, and in no way dependent on, the myriad cultural practices of the gay community).

So when did the real vampire community emerge and where did it come from? For some, the truth will undoubtedly be stranger than fiction. The terms "vampire community", "real vampire community" or "modern vampire community", as Browning (2014) lays out, did not see use until the late 1990s, and at that point they referred primarily to a network of online message boards, chat rooms and e-mail groups. Even still, a vastly disjointed network of people who self-identified as vampire had already existed for at least two decades. No one knows for sure just how many there were, but in the 1970s people who openly or secretively identified as vampire began regularly attending the same themed social gatherings and, in so doing, enabled to begin the process of networking with one another and identifying blood and energy donors. These social gatherings included Dark Shadows conventions and other vampire fiction and film fan organizations; bondage and S\&M events, which were frequented by blood fetishists and others whom real vampires found to be willing blood donors; Goth clubs; as well as variously affiliated pagan groups. Also appearing at this time in limited print runs were self-printed newsletters (or zines), which were especially helpful towards merging into one interconnected community the individual and small independent pockets of real vampires that peppered the United States.

The first research organizations dedicated to the study of vampires emerged in the 1960s. Jeanne Keyes Youngson, for example, founded in 1965 the Count Dracula Fan Club (now The Vampire Empire), an organization originally dedicated to Dracula and vampire fiction and film. However, after Youngson began receiving letters from real vampires, the organization's studies were extended, leading Youngson to publish a casebook of some of her more fascinating correspondence. The most notable early researcher, however, was Stephen Kaplan, who in 1972 formed the Vampire Research Center in Suffolk County, New York. There Kaplan supervised a "vampire hotline", which received numerous phone calls (many of them hoaxes) from real vampires. On several occasions, Kaplan made actual house calls to meet with some of his phone responders. The book in which Kaplan reported his findings remains a canonical, albeit problematic text in the field. Before long, other important figures begin to emerge, like Martin V Riccardo who in 1977 founded the Vampire Studies Society and printed quarterly newsletter entitled, Journal of Vampirism. In 1978, the Vampire Information Exchange emerged and published through to the mid-2000s the Vampire Information Exchange Newsletter. Other pertinent studies in the field were to follow in the 1980s as well as the 1990s, from scholars like Riccardo, folklorists like Norine Dresser, researchers and paranormalists like Rosemary Ellen Guiley, journalists like Carol Page and academic criminologists like Katherine Ramsland. The 1990s also brought two historically significant events in the growth and expansion of the real vampire community. The first was Anne Rice conventions, which provided closeted and unaffiliated real vampires with a bounty of opportunities for socializing and networking. Of more profound importance during this period, however, was White Wolfs Vampire: The Masquerade, a publication that laid the ground rules for a vampire roleplaying game and provided, if inadvertently, a social space within which real vampires could congregate and network openly. Vampire: The Masquerade introduced a lexicon, conventions, protocols and identifiers that the real vampire community adopted and adapted to its own needs. Thus emerged the predominant and somewhat unifying identity that persists today.

In the last decade, however, it is the Internet to which the real vampire community owes much of its prosperity. Whereas in the past real vampires existed in pockets or as isolated individuals and, to communicate, were therefore dependent on geographically close fan conventions and low-circulation newsletters, the Internet dissolved geographic limitations, made print correspondence almost entirely obsolete, and opened up vastly more efficient e-forums, chat rooms and e-communication. The 2000s have seen not only new scholarship treating real vampirism but works by actual members of the community itself, including Michelle Belanger, Corvis Nocturnum and Atlanta community leader Merticus of the Atlanta Vampire Alliance (AVA). The most important academic work of the last decade, however, 
as I will elaborate momentarily, has come at the hands of Joseph Laycock, followed by the shorter works of DJ Williams, John Morehead and myself.

Short popular writings on real vampirism have been so sparse that I am able to give here a near complete history. As more general works go, beneficial is Hoyt's (1984) Lust For Blood: The Consuming Story of Vampires, which, although focused on the history of supernatural vampires from ancient mythological accounts to twentieth-century accounts in both America and Europe, provides a sampling of modern-day accounts about American vampire "practitioners" and surveys briefly the more famous cases of blood-drinking serial killings. Melton's (1999) The Vampire Book: The Encyclopedia of the Undead is an invaluable first source, defining in minute detail major as well as minor terms that treat the various aspects of the vampire phenomena. Finally, Ramsland's (2002) The Science of Vampires offers interviews with vampire "practitioners", forensic experts and various specialists whose works and personal accounts explore the myths and modern-day realities of vampirism.

These next works are among the earliest to examine real vampirism more directly and served as the basis for much subsequent research. A canonical work in the field, Kaplan's (1984) Vampires Are is a compilation of Kaplan's findings on "real vampires" before a community existed. Also, Kaplan's Vampire Research Center was the first of its kind and would provide a model for future research centres and institutions. Dresser's (1989) American Vampires: Fans, Victims, and Practitioners examines various aspects of the vampire culture in America, from people who experience sexual gratification through blood-letting rituals and consumption, to lifestylers (or people who adopt the visual trappings of vampires), to fans merely obsessed with vampire media. Guiley's (1991) Vampires Among Us uses a more personal approach to present stories about people who identify themselves as vampires, while also considering the folkloric history of vampires and its influence on the modern-day real vampire scene. Page's (1993) Bloodlust: Conversations with Real Vampires, one of the first studies of its kind and now regarded as a seminal work in the field, offers interviews with and a detailed look at people who self-identify as vampire while discussing the various aspects of their day-to-day lives. Skal's (1993) The Monster Show: A Cultural History of Horror explores in one of its chapters the conflation between blood contamination and vampirism during the Regan years and even provides an interview between the author and a modern-day real vampire. In Ramsland's (1999) Piercing the Darkness: Undercover with Vampires in America Today, she uses the story of Susan Walsh, who disappeared while investigating vampire cults in 1996, to frame her own investigation into vampiric bloodletting, sexuality and body modification. And lastly, Youngson's (1997) Private Files of a Vampirologist: Case Histories \& Letters examines 11 case studies and 14 personal letters addressed to Youngson by people who self-identify as vampire.

Among the most recent studies (many by actual vampire writers) to begin exploring the vampire community as we understand it today is Guinn's (1997) Something in the Blood: The Underground World of Today's Vampires, which provides an introduction to the vampire subculture using interviews not only with people who identify themselves as vampires but people who have unwillingly fallen victim to so-called predatory vampires. Konstantinos's (2003) Vampires: The Occult Truth explores the occult truths behind vampires using first-person accounts that treat of not only the vampires of folklore but also modern-day psychic and sanguinarian vampires. Nocturnum and Filipak's (2009) Allure of the Vampire: Our Sexual Attraction to the Undead examines in detail culture's attraction to vampires by tracing their history in folklore, books and film, from ancient mythology to the modern-day vampire community. Russo's (2008) Vampire Nation dispels the centuries-old myths and rumours behind vampirism, provides accounts of actual vampirism and real-life narratives, and interviews modern-day vampires who reveal their feeding rituals and behavioural practices.

Works by Belanger, who self-identifies as a psychic vampire, have become some of the most important and respected in the field. Her The Psychic Vampire Codex: A Manual of Magick and Energy Work (2004) is now considered a canonical work in the field. It examines the history and everyday reality of the real vampire community, its cultural practices and esoteric language, from mere lifestylers to the difference between "psychic" and "sanguinarian" vampires, again the community's two main divisions. Belanger's (2005) Sacred Hunger compiles her major essays on the topics of vampirism, Bram Stoker, Dracula, modern-day psychic and sanguinarian vampires, and the history and development of the real vampire subculture. Finally, Belanger's (2007) Vampires in Their Own Words: An Anthology of Vampire Voices, for which she serves as editor, compiles various essays and personal narratives predominantly by and concerning people who identify themselves as vampires, as well as, to a lesser degree, wiccans and various other lifestylers who write on vampirism and various facets of the vampire subculture and lifestyle. By far the most valuable study on the modern-day vampire community, Laycock's (2009) Vampires Today: The Truth about Modern Vampirism explores representations of vampirism using extensive interviews predominantly with members of the AVA as well as a few other vampire communities throughout the United States. This work examines not only real vampires, who, as I have said, report feeling a natural attraction towards blood and energy consumption, but lifestylers as well who have adopted the Gothic aesthetic that has come to be associated with the vampires of media. Laycock's book, which has proven to be indispensable in understanding the real vampire community, its infrastructure and its organizational history, now serves as a canonical study in the field. There is also a small body of (problematic) socio-religious writings on the real vampire identity that Laycock $(2010)$ outlines in his more recent work. Finally, Williams (2008, 2009, 2013), and Browning (2010a, b, 2011), treat of the creative, therapeutic, self-liberating and antinormative nature of real vampirism.

\section{Methodology and study documents}

I have approached my New Orleans (2009-2011) and Buffalo (2011-2013) studies using multiple resources, tools and techniques. The texts outlined in the previous section are among the most valuable of these resources in providing the study with a conceptual framework with which to proceed. Two of these texts in particular provided valuable insight into current vampire research and terminology, thereby enabling me to assemble what has become perhaps this study's most research valuable tool: the participant "Questionnaire", which I shall examine in-depth momentarily. Other valuable tools included my satchel, clipboards, writing utensils and a digital voice recorder. Other, less crucial tools included latex gloves (in the event I was expected to examine a participant's fangs, or witness the process of exsanguinationthat is, the blood-letting ritual performed between a sanguinarian vampire and his or her donor) and a flashlight (in the event my study brings me to a dimly-lit field site). Lastly, among the techniques I utilized for these studies included field notes, as well as observations conducted at various locations throughout the French Quarter (New Orleans), including Gothic apparel shops, night clubs, sidewalks and alleyways.

"General Questionnaire A-2" provided this study's most crucial data. Of the 15 (14 active) participants in the New Orleans study 
and 4 in the Buffalo study, approximately 13 have completed this questionnaire. It includes the prefatory statement, "Please briefly answer the following questions as specifically or generally as you feel comfortable with. Please do not answer any question you do not want to", followed by 36 questions, the answers to which offer valuable insight into the lives and cultural practices of the participants. The questions were as follows:

1. Name, or alias?

2. Birthday?

3. Since high school, what jobs have you held?

4. Present occupation?

5. Do you live in New Orleans/Buffalo? If not, where then, and why are you presently living in your present location?

6. Sexual orientation?

7. Married? Children?

8. Are you a vampyre, or vampire, or any variation thereof?

9. How long have you been a vampyre?

10. Do you feel you were born a vampyre, or were you somehow initiated into it, or both?

11. Do you have fangs? Please describe them?

12. Do you consume human blood? Animal blood? Both?

13. Do you consume psychic energy?

14. Define psychic energy?

15. Describe your first blood-drinking, or psychic energyabsorbing, experience?

16. Does the site or taste of blood or psychic energy arouse you sexually?

17. When and how did you first know you were a vampyre?

18. Why do you consume blood or psychic energy, or both?

19. What does blood taste like, specifically?

20. How do you feel while you consume blood or psychic energy? After?

21. Do you prefer blood to be chilled or warm, or both? Mixed with another liquid? Other?

22. Do you store blood, and if so how?

23. Have you ever become sick after consuming blood?

24. How much blood or psychic energy do you consume at one time?

25. How often do you need to consume blood or psychic energy?

26. What, if anything happens if you don't consume blood or psychic energy?

27. What effect do you think consuming blood or psychic energy has had on your life?

28. Where do you get the blood or psychic energy? If donors, describe them?

29. How do you extract the blood or psychic energy?

30. How did you learn to extract blood or psychic energy?

31. How do you feel if you don't consume blood or psychic energy?

32. Has your health changed since you started consuming blood or psychic energy?

33. Has your appearance changed since you started consuming blood or psychic energy?

34. What type of bed do you sleep in?

35. What other foods do you eat? How much? How often?

36. What is the most convenient way for me to contact you again? Specify?

\section{Fieldwork, field site(s) and "reel" vampirism}

I should like to say a few words now on the specific habits and cultural identificatory markers predominant among real vampires. Doing so will help to dispel a few myths or misconceptions. Real vampires do not generally sleep in coffins (though certainly some have and do), and they do not claim to live forever. Indeed, real vampires diffuse beyond the realms of film and literature in which popular culture has traditionally situated them. Real vampires are living people, generally leading what may be deemed everyday lives, and who, according to what I and other scholars have been able to ascertain, appropriate the figure of the vampire and adapt it for self-identificatory purposes. This, however, they do only after-in many cases, years after-the compulsion to take blood or energy arises. Even still, this is not to say that some of the fictional vampire's more obvious cultural and socio-historical dimensions in film and literature are not reflected in real vampires.

Aside from blood-drinking and feeding on energy, a sizeable number in the real vampire community prefers to don Gothic apparel (though certainly not all the time), and many will even don prosthetic fangs, a practice that, for the most, is purely aesthetic, though it can and does serve a cultural need, especially in New Orleans where fangs contribute to inter-communal identification. Scholars and curious observers interested in real vampire communities around the world have begun to probe this subculture with renewed vigour to ask why, partly in an attempt to gain new insight, but for some regrettably it is to disqualify, or suppress I think, this identity group. I suspect that latter does so mainly out of a host of misconceptions as the "real" and the "reel" continue to blur more and more seamlessly into one another in and outside of the vampire subculture. There has even transpired, upon closer scrutiny, a certain degree of cross-pollination between the two realms. That is to say, the more "Goth" or "Steampunk" variety of self-identifying human vampires-which, in fact, comprises only a portion of the vampire communityseems to be informing with increasing regularity the representations of vampires we see in film, television and literature (not just the other way around). The process has become recursive. Thus, to divorce completely this subculture from literary and filmic representations is to deny it its modernity.

Similar may be said for denying real vampires of their humanity. In my own dealings with the real vampire community in New Orleans and Buffalo, I found its members to be kind, accommodating and pleasant to be around. To my surprise, some were loving parents whose children accompanied them to vampire community meetings. Some could have passed for everyday "professionals" one might pass on the street, while others were only too eager to embrace the latest Gothic fashions. All of them, however, regardless of their choice of personal attire, showed what I can only describe as admirable strength and courage in the face of immense opposition to their identity. Equally important, they behave-and survive-as a community(s).

Curiously, though perhaps not surprisingly, these communities are represented through an amalgam of identities and experiences. The real vampires I met and interviewed ranged in age from approximately 18-50; represented both sexes equally; practiced sanguinarian and/or psychic feeding; described themselves as atheistic, monotheistic or polytheistic; self-identified as heterosexual, homosexual and bisexual; some were parents; married and divorced; and were wearing or have worn fangs, or had, or have had, naturally long incisors. Unquestionably, I found the members of this community to be competent citizens, that they performed blood-letting and other similar rituals safely and did so only with willing donors, and participated regularly in medical checkups that scarcely (if ever) indicated complications as a result of their feeding practices.

The French Quarter, the central research site chosen for the New Orleans study, is particularly germane to this line of enquiry, as there are, I would imagine, few other research sites in which such a vastly diverse ethnic and cultural makeup may be observed to coexist in the open. It is also here, in the French Quarter, that I encountered all of my Louisiana participants. During the initial 
stages of this study, I was completely overcome with excitement and curiosity, and had very few expectations as to what, or whom, I would find. I must not omit to say, however, that I felt a certain amount of hope, which is something quite different from expectation, and it was hope that permitted a certain level of delusion to set in very early on. Early on, I think on a subconscious level I romanticized the research process. The longer it took me to locate my first participant, the more my delusion morphed and shaped how I imagined "my first time" (as I called it) would be. Finally, at Wicked New Orleans, a Gothic apparel shop, the opportunity arrived. The shop owner, with whom I was engaged in conversation, suddenly stopped me midsentence and advised me to go speak to a woman who had entered his shop, a woman he claimed was a "vampire". I was completely unprepared for this; I never imagined "my first time" would be in a leather shop. Swallowing my pride, I walked over to the unsuspecting woman in her 40s-50s (whom I shall call "Jennifer"). I explained to Jennifer who I was and what I was doing in the French Quarter, to which she smiled and revealed her teeth (some of which had been filed down to a point). I made friendly conversation for a moment (and looking back, I cannot even remember what I said) then gave her my contact information, asking politely that she call or e-mail me at some point. Never, not for one second, did I think I would not see or hear from her again; but I did not. My first chance had come and gone, and I blew it.

As I began delving into some of the field's early scholarship, particularly Kaplan's work, I realized the difficulties I had been facing were nothing new to studies in real vampirism. Before going out into the field again, I poured over several scholarly and popular works, and eventually took a new initiative: Treat all future encounters with participants as though I would never see or hear from them again after the initial contact. To prepare, I compiled the "Questionnaire" and carried several copies with me, I brought along clipboards (for the participants to write on), latex gloves (in case of inspection involving blood or teeth), a flashlight (in case my research took me into dark places or homes) and a digital voice recorder (in case a participant refused to write his or her answers but agreed to verbalize them). Although my satchel grew heavier, my workload grew lighter, as the strategy would eventually pay off.

After Jennifer, almost another 2 months would pass before I could locate more participants for my study. A chance opportunity came one October night in 2009, however, when I frequented a club in the French Quarter called, "The Dungeon". In the space of $2 \mathrm{~h}$, I met there and documented five vampires. Among them were "Maven", mid-30s, a "fangsmith" (designer and sculptor of made-to-order vampire fangs) of some repute I gathered and would later verify, and a local vampire elder ${ }^{2}$; a vampire named "Max", Maven's sidekick, late-teens/early-20s, and a martial artist; a vampire named "Torch" (with whom I have now lost contact), mid-20s, quiet demeanour and elusive; a vampire I shall call "Victoria" (with whom I have now lost contact), Torch's girlfriend, late-teens, excited by the prospect of participating in the study; and a vampire I shall call "James", early-30s, who was initially hesitant to participate. The challenges, however, were far from over. All five participants left contact information in the "Questionnaire", but only one phone number proved to be legitimate. This fact was rather an unfortunate one. However, after concluding my field observations at The Dungeon, something occurred to me after the fact: all the vampires who were present that night at the club arrived in separate, smaller groups: Maven and Max, Torch and Victoria, and James. Yet, all five participants knew each other by name, which suggested to me at the time at least a certain level of what one might call communiality. How, I remember thinking, would I ever be able to find this community if I could not even get one of its members to call me back or disclose an accurate e-mail address. It turned out I would only have to wait about a month.

Laycock (2009) aptly remarks that the public generally only hears about the real vampire community in the media following some "vampiric" serial murder, or during October as a means to exploit the season of death and monsters. Unfortunately, the New Orleans vampire community has not escaped Laycock's assessment. An ABC 20/20 special on New Orleans's real vampires broadcasted that October, one that, according to the community, sensationalized the whole ordeal by editing down their interviews and mixing and matching some of the questions and answers, incorporating into the programme the use of Gothicized music, images and other similar tropes, and in effect turning the whole account into a twisted fantasy. Another painfully negative outcome of the broadcast occurred in the Discussion/Comment Board that accompanied the video at ABC's Website. As Browning (2010b) discusses at length, on it are statements from viewers who, to some degree, support the vampire community or one's freedom of expression, but far more frequent were statements by unsupportive, misled or utterly irate viewers whose comments were unfounded and born out of assumptions, misconceptions and misinterpretations about the real vampire identity and community.

One of the vampires featured in the 20/20 broadcast was "Belfazaar ('Zaar') Ashantison", a resident of New Orleans and a member of a community-wide council of vampire elders called the New Orleans Vampire Association (NOVA). It was through him, after meeting his expectations and gaining his trust through our initial interview, that I met over the next few weeks 10-12 additional members of the community, all of whom generously agreed to participate in my study. "Zaar" was in his early-40s, a local vampire elder, and a founding member of NOVA. I encountered the next eight participants at the initial NOVA meeting I attended: a vampire named "Corrien", who looked to be in her late-30s; a vampire named "Reverend Boone", in his late30 s/early-40s, who looked to be the most menacing of those in attendance to the meeting; a vampire I shall call "Meph" (short for "Mephistopheles"), a local vampire elder who suffers from a debilitating physical illness and therefore walked with a cane (a Barnabas Collins's Dark Shadows replica); a vampire named "Jade", a local vampire elder who looked to be in her mid-30s; a local vampire elder named "Reverend Jezabel de Luna" (or "Jez"), a larger than life female who looked to be in her mid-30s; a local vampire elder I shall call "Lorilee", who looked to be in her mid40s; a vampire I shall call "Tony", who is a local tour guide, a local vampire elder and looked to be in his early-40s; and a vampire I shall call "Erin", Tony's girlfriend who looked to be in her late-30s. In time I would meet other vampires as well.

After I moved from New Orleans to Buffalo in Summer 2011, I was immediately interested in whether or not Buffalo had its own real vampire community and if it was similar to New Orleans's. Perhaps "geography", I thought, would offer another fruitful context within which to frame the fundamental relationship of the vampire identity to its cultural construction. Whether geographical specificity could yield insights into the more generalized umbrella of vampire self-identification became for me a new and fascinating avenue worth exploring. To carry out this new supplemental study, I planned to use the following research methods: contact leading members of the vampire community at large and through them obtain contact information for persons living in Buffalo who meet one of the categories given previously; frequent night clubs in the greater Buffalo area whose attendees either appropriate "Gothic"style themes, or that are rumoured to be frequented by persons who meet one of the categories given previously, or both; post, in local newspapers and public $e$-forums, ads that describe my study 
and invite qualified persons to participate; frequent local stores that sell "Gothic"-themed goods, and there speak with the owner and workers, describe my study, ask about potentially qualified persons and leave at the store my contact information to be handed out accordingly.

Using information gathered over a period of several months from interviews and field observations, it was my intention for this supplementary study to provide behavioural and sociocultural data geographically specific to study participants inhabiting the greater Buffalo area. Contrasting this study with the previous one would, I hope, allow me to perceive qualities of each field site that might otherwise appear to the average observer as "normal", unrelated or universal. While conducting the study, I took along with me, just as I did in New Orleans, my trusty brown satchel containing IRB consent forms, pad and pen, flashlight, voice recorder and latex gloves. What I eventually found, through comparative analysis, was that my experiences with vampire self-identification in New Orleans yielded quite a lot about vampire identity construction in Buffalo, but it had less to do with similarities. Geography, it would seem, played a much greater part than perhaps any of us in the field had realized.

I began my study in Buffalo by first contacting through e-mail the people living there whose contact information I had received from leading members of the real vampire community. It was also my intention to frequent Gothic-styled night clubs or other places generally rumoured to be frequented by real vampires. However, neither was to be had, mainly because they simply did not exist as far as I could ascertain, though Club Diablo (now closed) was mentioned, albeit dubiously, as a potential site. Even still, my experiences in Buffalo were in some ways similar to New Orleans, though in many other ways they were quite different. For example, the term "ronin", used by the vampire community at large to denote an individual vampire who is not affiliated with a particular house, coven and so on, was applicable to only a handful of vampires living in New Orleans. In Buffalo, however, the use of this term was universal, as the five vampires I encountered were not affiliated with any group, nor did any such group seem to exist within the city or outlying suburbs.

One of my study participants in Buffalo, whom I shall call simply "Christy" (early-30s), was a psychic vampire. Contact with Christy was confined to the Internet. We made several attempts to meet in-person, but conflicting schedules, illness and finances prevented this. There was also, with Christy, a strong issue of confidentiality. This was due in large part to an extenuating circumstance that made her situation quite different than any I encountered in New Orleans. Her partner with whom she lived at the time was not fully aware of the extent of her vampire selfidentity, and what little he had been told he reacted negatively to. Additionally, Christy was engaged in the process of trying to gain custody of her daughter and felt (aptly so I think) that knowledge of her self-identity would impede that effort. The next two vampires in my study came as a pair: Serevus (male, 36) and Shyla (female, 19), who at the time were engaged to be married. Both were psychic vampires, and identified primarily as tantric feeder, which is to say they absorbed energy through sexual and erotic encounters. Shyla explained to me that this particular method is often misunderstood, that folks outside and even some within the real vampire community look at it as merely a craving for sex: "[S]ince I realized that I was a sexual vampire, I was really into the attraction-just the feelings. It's not even just sex in itself, but the actual people flirting and things like that. It's something I feel. And, you know alot of people don't understand it". I met with Serevus and Shyla together at a local Buffalo eatery on three occasions, and later I conducted interviews with each separately at a local prominent coffee shop. In both instances I found them to be very friendly and quite attuned not only to their self- identities but to the cultural practices of the vampire community at large. Although neither was affiliated with a vampire house, both were up-to-date on national and community-wide activities and practices; this contrasted greatly with my New Orleans participants, all of whom were members or leaders of a local vampire house but gave noticeably less attention to general, community-wide matters unless they were pertinent to New Orleans. Serevus and Shyla seemed adamant about starting their own household in Buffalo (a dream made all the more possible, they claimed, as a result of my study).

Contrasting these geographical studies through the use of interviews and field observations gathered from each field site has helped to accentuate place-specific behavioural and socio-cultural factors. On that note, it is worth mentioning as well that Halloween meant far less to the Buffalo identity than it did in New Orleans. For many in the vampire community, October in general, and Halloween in particular, can be a profitable time of year. Vampire organizations like the one I shadowed in New Orleans, fangsmiths (who construct prosthetic fangs for vampires), vampire event performers, and individual members and houses of the vampire community, all converge on large cities like New York, New Orleans and Atlanta, and in cities across the world, to participate in ceremonies and take part in celebration and fellowship. This is especially true for New Orleans, which plays host to some of the largest vampire events in the country. However, although the fruit of such gatherings is profit for the organizations and private parties who, in turn, feed that money back into their respective vampire communities and organizations, these profits are also vital to fuelling local charity events, such as those organized by Zaar and NOVA like feeding the homeless (at times, as many as $80-100$ mouths) at Christmas, Easter and Thanksgiving or aiding those in general need, and to perpetuating the organizations who pride themselves on giving back to their local communities. This speaks voluminously of the vampire identity, which, to the outside world, is often associated purely with excess, psychopathology and a general sense of disconnection from community involvement. The reality, as I have tried to show, is actually far different. Modern vampires, through reconciling these and other, similar antitheticals, effectively critique ideological systems that dictate how normalcy should be constructed. Indeed, their metaphysical understandings of themselves and what they regard as their innate condition serve to "challenge", as one external reader of this article found, "the authority of contemporary power structures and normalizing discourses of both western religion and modern medicine and psychiatry" ${ }^{3}$ In short, normativity is of minimal practical use to real vampires and serves little more than to recall for them hurtful memories of a repressive and oppressive system that shuns more than it embraces.

\section{Closing remarks}

Often we think of culture and otherness as mutually exclusive entities, the former always preceding, and generally dictating, the latter. But must they always exist along such a narrow continuum, or can the two accommodate between themselves a level of reciprocity? Indeed, I have found that they can, but more pertinently, how is this achieved? How can otherness achieve a mutual and recursive dialogue with culture? One answer may lie within deviant subcultural formation or, to put another way, what I term defiant culture. In what ways are marginalized groups key to understanding some larger dynamic? And how can otherness become, indeed, part of a broader cultural analysis? This remains a large, interesting yet unresolved problem.

My use of the term "subculture" as an analytical tool to describe the real vampire community is informed predominantly 
by the work of Australian Literary and Cultural Studies professor Ken Gelder. According to Gelder (2007), subcultures share a "common narrative" as nonconformist and, thereby, nonnormative. At least six "prevailing cultural logics", by Gelder's account, exist for identifying subcultures (3-4):

1. Routinely, members of a subculture are judged or conceived by the outside in negative terms in relation to labour. They may be considered idle or lazy, even too leisurely, or they may partake of work related to their own subculture that is looked upon by the outside as parasitical, counter to "legitimate" work or even illegal.

2. A subculture's relation to class is only vaguely understood. Some subcultures are even seen as digressing completely from their class, discarding any class affiliation or " 'transcending' class as a result of the particular cultural adjustments they have made".

3. Property ownership is seen as somehow antithetical to subcultural identity. For, subcultures tend to territorialize, rather than own, a geographical location or area, in this way creating new modes of expression and belonging that is based in part on place.

4. Typically, subcultures congregate outside the domestic sphere. For youth in particular, it is this "initial deviation from home and the subsequent adjustment into subcultural forms of homeliness and belonging" outside the domestic family unit that earmarks subcultural identity.

5. Public or "cultural logic", as Gelder puts it, has a tendency to see subcultures as excessive or exaggerated. In this case, the "deviance" of subcultures is attributable, at least in part, to an excess of characteristic traits spanning behaviour, dress, sounds and so on, as well as, I would add, esoteric knowledge, all of which are contrasted with "normal" society's conceptions of moderation and restraint.

6. Finally, the remaining cultural logic concerns a subculture's inherent "opposition to the banalities of mass cultural forms". By this is meant that subcultural identity embraces a nonconformist stance towards societal massification, that is, self-alienation.

Each of Gelder's cultural logics is indicative both of the real vampire subculture and external perceptions of it. At a glance, the use of my term "defiant culture" would seem, then, to be synonymous with subculture. Therefore, further explanation is needed. My term is an appropriation of the work of Christina Santos and Adriana Spahr on "defiant deviance". Santos and Spahr (2006) examine the ways in which the supernatural persists as a recurring element in mass media and culture, despite its general obsoletion at the hands of the Enlightenment. The persistence of the supernatural-in art, literature, film and so on -is for Santos and Spahr a "defiant form of deviance": "a state of opposition and a disposition to resist that deviates from the accepted norm" (1). Put another way, society's free embrace of supernatural figures and the paranormal, in spite of prevailing technological and scientific knowledge, is intentionally defiant, that is, a deviation intended by design to defy. Although Santos and Spahr do apply their term to a single case study of alleged vampirism ("by association only", the authors note) in the person of Countess Erzsébet Báthory (1560-1614) of Hungary, their work fails to account for actual self-identification with vampirism, of which, perhaps unbeknownst to them, there is an entire interconnected, subcultural community populated with members who do just that. As for Gelder, his cultural logics, although productively inclusive, seem also hardly adequate to surmise a subculture considered by the outside to be so deviant and so aberrant that the very nature of its identity is by many altogether discounted. The real vampire community is, to be sure, a subculture like no other. It is what I term a "defiant culture"; this is to say, it manifests its own deviance through the act of defiance for its own sake, in this case, the conscious use of a negative identifier like "vampire". Laycock (2010) is apt to note that "The idea that the real vampire community is formed by an inherent quality", that is, biology, "rather than subcultural participation is reflected in the structure of the community, which is dialogical and acephalous" (8). Yet I contend that the appropriation of the word "vampire" and the vampire milieu is at least as important, producing as a result a community that is both "defiant" and iconoclastic.

Beyond mere physiology, however, what particularly strikes me are the ways in which the very being and nature of this community are subversive to how societies construct "normalcy". It becomes important to ask, then, whether the history of real vampires can help to address the broader relation between culture and otherness. Real vampires comprise, as I have said, a subculture the outside considers so deviant and so aberrant that its very nature is altogether discounted. Yet, simultaneously, this distinction is crucial to the real vampire community's status as a "defiant culture": through manifesting its own deviance by means of defiance for its own sake, it achieves as it were a degree of selfempowerment. Heiner's (2008) sentiment that "One of the more resounding principles in the sociology of deviance is that the defining quality of deviance resides in the audience and not in the person or behavior" (xi) is something I have tried to emphasize in my work on real vampires, in addition to whether identity construction among "alternative" subcultures in the United States in general and in New Orleans and Buffalo in particular can aid in redefining the dominative and corrective moral and behavioural imperatives societies use to construct "normalcy". Ironically it is these same imperatives, borrowing loosely from the work of Eve Sedgwick, that make the modern vampire identity a strategic site for confronting, and challenging, ideological assumptions culturally and historically imbedded in the methods by which we as a society hierarchize the world around us (Browning, 2012). Modern vampires are capable of making accessible the infinite potentials for exposing and, with any luck, unfixing the repressive and oppressive categories that precipitate marginalization. In short, modern vampirism offers a valuable lens through which to understand and, perhaps, dispel some of the ideological "baggage" each of us carries; through them, we see the dark side of ourselves. Yet the subject of modern vampires would not be nearly as interesting, or as "radical", were it not perceived as being so "deviant". Thus, the study of modern vampirism is, in a broader sense, the study of "deviance". However, it is also the study of "defiance" and self-empowerment.

\section{Notes}

1 Geographical areas, individual houses and even individual members of the real vampire community will independently render the word "vampire" as "vampyre" as a means of distinguishing the community from the supernatural archetype of fiction and film. The rendering "vampi(y)re" is also sometimes used as a compromise to satisfy proponents of each spelling.

2 Sanguinarius defines "elder" thusly: "A prominent member of the vampiric community who is honored and respected for his or her experience, knowledge, willingness to help others, accomplishments and devotion. Elders are often those individuals who have helped establish a community, organize groups, or help network the community" (13). See Sanguinarius (2010) and also Merticus (2014).

3 I am grateful to an external reader of this article for this succinct observation and phrasing.

\section{References}

Belanger M (2004) The Psychic Vampire Codex: A Manual of Magick and Energy Work. Weiser: Newburyport, MA.

Belanger M (2005) Sacred Hunger. Dark Moon Press: Fort Wayne, IN. 
Belanger M (ed) (2007) Vampires in Their Own Words: An Anthology of Vampire Voices. Llewellyn: Woordbury, MN.

Browning J E (2010a) Interviews with the vampires: The real story behind New Orleans' vampire subculture. Deep South Magazine. Available from: http:// deepsouthmag.com/ [Spring]. Reprinted in: Summers M. The Vampire in Europe: A Critical Edition. Apocryphile Press: Berkeley, CA, pp 378-381.

Browning J E (2010b) Conversations with real vampires. Deep South Magazine. Available from: http://deepsouthmag.com/ [Fall]. Reprinted in: Summers M. The Vampire in Europe: A Critical Edition. Apocryphile Press: Berkeley, CA, pp 381-389.

Browning J E (2011) The dangerous dead: Vampire mythology in the house of night series. In: Cast P C (ed) Nyx in the House of Night. Smart Pop: Dallas, TX, pp 13-29.

Browning J E (2012) Towards a monster pedagogy: (Re)claiming the classroom for the other. In: Moreland S, Ahmad A (eds) Fear and Learning: Essays on the Pedagogy of Horror. McFarland: Jefferson, NC, pp 40-55.

Browning J E (2014) The real vampire community: A concise history. In: Summers M (ed) The Vampire in Europe: A Critical Edition. Apocryphile Press: Berkeley, CA, pp 368-370.

Dresser N (1989) American Vampires: Fans, Victims, and Practitioners. W. W. Norton and Company: New York.

Gelder K (2007) Subcultures: Cultural Histories and Social Practice. Routledge: New York.

Guiley R E (1991) Vampires among Us. Pocket Books: New York.

Guinn J (1997) Something in the Blood: The Underground World of Today's Vampires. The Summit Publishing Group: Ottawa, ON.

Heiner R (2008) Deviance across Cultures. Oxford University Press: Oxford.

Hoyt O (1984) Lust for Blood: The Consuming Story of Vampires. Scarborough House: Lanham, MD.

Kaplan S (1984) Vampires Are. ETC Publications: Palm Springs, CA.

Konstantinos (2003) Vampires: The Occult Truth. Llewellyn Publications: St Paul, $\mathrm{MN}$.

Laycock J (2009) Vampires Today: The Truth about Modern Vampirism. Praeger Press: Santa Barbara.

Laycock J (2010) Real vampires as an identity group: Analyzing causes and effects of an introspective survey by the vampire community. Nova Religio: The Journal of Alternative and Emergent Religions; 14 (1): 4-23.

Melton J G (1999) The Vampire Book: The Encyclopedia of the Undead. 2nd edn. Visible Ink Press: Detroit, MI.

Merticus (2014) Pitfalls, mousetraps \& elders of the vampire community. Vampire Community News (VCN): Real Vampire Subculture News \& Article Syndication, accessed at: http://merticus.com/vampirenews/2014/01/16/elders/.

Nocturnum C and Filipak C (2009) Allure of the Vampire: Our Sexual Attraction to the Undead. CreateSpace: Scotts Valley, CA.

Page C (1993) Bloodlust: Conversations with Real Vampires. Warner Books: London. Ramsland K (1999) Piercing the Darkness: Undercover with Vampires in America Today. Harper Paperbacks: New York.
Ramsland K (2002) The Science of Vampires. Berkley Boulevard Books: New York. Russo A (2008) Vampire Nation. Llewellyn Publications: Woodbury, MN.

Sanguinarius (2010) The Dictionary of Vampspeak: Terminology and Lingo in the Vampire Community. 2nd edn. Arizona: Sanguinarius.org.

Santos C and Spahr A (eds) (2006) Introduction to Defiant Deviance: The Irreality of Reality in the Cultural Imaginary. Peter Lang: Switzerland.

Skal D J (1993) The Monster Show: A Cultural History of Horror. Penguin Books: New York.

Williams D J (2008) Contemporary vampires and (blood-red) leisure: Should we be afraid of the dark? Leisure/Loisir; 32 (2): 513-539.

Williams D J (2009) Deviant leisure: Rethinking "The good, the bad, and the ugly". Leisure Sciences: An Interdisciplinary Journal; 31 (2): 207-213.

Williams D J (2013) Social work, BDSM and vampires: Toward understanding and empowering people with non-traditional identities. Canadian Social Work; 15 (1): $10-24$.

Youngson J K (1997) Private Files of a Vampirologist: Case Histories \& Letters. Adams Press: Chicago, IL.

\section{Acknowledgements}

Much thanks is owed to SUNY-Buffalo professors Michael Frisch, Bruce Jackson and Sarah Elder, who provided helpful feedback on my research. Ethnographic materials and research underpinning this study such as field notes, digital audio recordings, transcripts, ephemera collected onsite and internal NOVA documents are deposited with the author under secure lock and key for the purpose of protecting the personal identities of the study participants. Copies of individual consent forms wherein full identification is not disclosed can be requested by outside parties. A more extensive elaboration of this research, including or in addition to the ethnographic materials listed above, is forthcoming in a book-length project currently in progress.

\section{Additional Information}

Competing interests: The author declares no competing financial interests.

Reprints and permission information is available at http://www.palgrave-journals.com/ pal/authors/rights_and_permissions.html

How to cite this article: John Edgar Browning (2015) The real vampires of New Orleans and Buffalo: a research note towards comparative ethnography. Palgrave Communications 1:15006 doi: 10.1057/palcomms.2015.6.

(c) (i) This work is licensed under a Creative Commons Attribution 3.0 International License. The images or other third party material in this article are included in the article's Creative Commons license, unless indicated otherwise in the credit line; if the material is not included under the Creative Commons license, users will need to obtain permission from the license holder to reproduce the material. To view a copy of this license, visit http://creativecommons.org/licenses/by/3.0/ 